\title{
MZB1 expression indicates poor prognosis in estrogen receptor-positive breast cancer
}

\author{
MANABU WATANABE ${ }^{1,2}$, MASAHIRO SHIBATA ${ }^{2}$, TAKAHIRO INAISHI ${ }^{2}$, TAKAHIRO ICHIKAWA ${ }^{2}$, \\ IKUMI SOEDA $^{1,2}$, NORIYUKI MIYAJIMA ${ }^{2}$, YUKO TAKANO ${ }^{2}$, DAI TAKEUCHI ${ }^{2}$, NOBUYUKI TSUNODA $^{1,2}$, \\ MITSURO KANDA $^{3}$, TOYONE KIKUMORI ${ }^{2}$, YASUHIRO KODERA ${ }^{3}$ and MASATO NAGINO ${ }^{1}$ \\ ${ }^{1}$ Division of Surgical Oncology, Department of Surgery; Departments of ${ }^{2}$ Breast and Endocrine Surgery and \\ ${ }^{3}$ Gastroenterological Surgery, Nagoya University Graduate School of Medicine, Nagoya, Aichi 466-8550, Japan
}

Received March 26, 2020; Accepted August 18, 2020

DOI: DOI:10.3892/ol.2020.12059

\begin{abstract}
Breast cancer (BC) is the most common malignant tumor in females. Development of novel biomarkers or therapeutic targets may contribute toward the improvement of a patient's prognosis. Marginal zone B and B1 cell-specific protein (MZB1) is an unfolded protein response-related chaperone and mainly exists in the endoplasmic reticulum of B lymphocytes, although little is known regarding its role in BC cells. The present study aimed to investigate the significance of MZB1 expression in BC. To begin with, $M Z B 1$ mRNA expression levels in $13 \mathrm{BC}$ cell lines and two non-cancerous mammary cell lines were evaluated. Next, mRNA and protein expression of MZB1 in BC patient tumor specimens was evaluated to assess the association between expression and clinicopathological factors or prognosis. $M Z B 1$ mRNA expression levels were detectable in four estrogen receptor (ER)-positive BC cell lines. When ratios of $M Z B 1 \mathrm{mRNA}$ expression levels between $\mathrm{BC}$ and non-cancerous specimens were evaluated, patients with stage III disease exhibited a higher ratio than patients with stage $0 / \mathrm{I} / \mathrm{II}$ disease $(\mathrm{P}=0.009)$. Using immunohistochemistry, patients with
\end{abstract}

Correspondence to: Dr Masahiro Shibata, Department of Breast and Endocrine Surgery, Nagoya University Graduate School of Medicine, 65 Tsurumai-cho, Showa-ku, Nagoya, Aichi 466-8550, Japan

E-mail:m-shibata@med.nagoya-u.ac.jp

Abbreviations: BC, breast cancer; DDIT3, DNA damage inducible transcript 3; DERL3, Derlin 3; DFS, disease-free survival; ER, estrogen receptor; ER $\alpha$, estrogen receptor $\alpha$; GAPDH, glyceraldehyde-3-phosphate dehydrogenase; GRP, glucose-regulated protein; HER2, human epidermal growth factor 2; HSP, heat shock protein; IRE1, inositol requiring enzyme 1; MZB1, marginal zone B and $\mathrm{B} 1$ cell-specific protein; OS, overall survival; $\mathrm{PgR}$, progesterone receptor; RT-qPCR, reverse transcription-quantitative polymerase chain reaction; UICC, Union for International Cancer Control; $\mathrm{XBP} 1, \mathrm{X}$-box binding protein 1

Key words: breast cancer, MZB1, chaperone, ER-positive, prognostic marker
ER-positive BC more frequently expressed MZB1, compared with patients with ER-negative $\mathrm{BC}(\mathrm{P}=0.003)$. In patients with ER-positive BC, patients with MZB1-positive BC experienced shorter disease-free survival (DFS) times than patients with negative $\mathrm{BC}(\mathrm{P}=0.026)$. Multivariate analysis of DFS demonstrated that MZB1 positivity was an independent prognostic factor $(\mathrm{P}=0.022)$. The results of the present study suggested that MZB1 expression may be associated with a more advanced stage of BC. Furthermore, in patients with ER-positive BC, MZB1 may be a potential prognostic marker.

\section{Introduction}

Breast cancer $(\mathrm{BC})$ is the most prevalent malignancy in females worldwide (1). Recently, in addition to conventional medication therapies, including chemotherapy, endocrine therapy, and anti-human epidermal growth factor 2 (HER2) drugs, several molecular-targeting drugs and immunotherapies have been developed for patients with BC. However, despite these various therapeutic strategies, it remains difficult to achieve a cure for patients with metastatic disease due to the pleiotropic properties of BC (2). Therefore, the development of novel biomarkers or therapeutic targets focused on these diverse activities or pathways in $\mathrm{BC}$ cells is required to improve a patients' prognoses.

In our previous study on gastric cancer, transcriptome analysis was used to identify marginal zone B and B1 cell-specific protein (MZB1) as a potential novel prognostic biomarker (3). Previous reports regarding MZB1 as a prognostic marker were inconsistent possibly as a result of the organ-specific function of MZB1 $(4,5)$. MZB1 is a molecular chaperone that cooperates with other chaperones, including glucose-regulated proteins (GRPs) in the endoplasmic reticulum (6). When cancer cells undergo endoplasmic reticulum stress, which may be brought on by hypoxia and a lack of nutrients, an increase in misfolded proteins occurs and activates the unfolded protein response (UPR), which leads to cancer progression (7-9). In BC, UPR-related molecules, including X-box-binding protein 1 (XBP1) and GRP78, have been reported to be upregulated in tumor specimens from patients with more advanced BC $(10,11)$. In addition, our previous study reported that Derlin 3 (DERL3), which is upregulated in the 
UPR pathway, contributes toward cancer progression, and high $D E R L 3$ expression levels indicate poor survival in patients with BC (12). Although no clinically available biomarker or drug has targeted these UPR-related pathways or molecules, these results suggested the promising possibility of using these UPR-related molecules as novel biomarkers or drug targets. However, there have been no reports that refer to the activity of MZB1 in BC.

The present study investigated the significance of MZB1 expression and evaluated whether MZB1 may be a biomarker in $\mathrm{BC}$.

\section{Materials and methods}

Sample collection. Thirteen BC cell lines (BT-20, BT-474, BT-549, HCC1419, HCC1954, Hs578T, MCF7, MDA-MB-231, MDA-MB-361, MDA-MB-415, MDA-MB-468, SK-BR-3 and ZR-75-1) and two non-cancerous breast epithelial cell lines (MCF-10A and MCF-12A) were used in the present study. BT-549, HCC1419, HCC1954 and Hs578T cell lines were purchased from the Japanese Collection of Research Bioresources Cell Bank (Osaka, Japan), and BT-474, MCF-7 and MCF-12A were gifted by Professor David Sidransky of Johns Hopkins University (Baltimore, MD, USA). All other cell lines were purchased from the American Type Culture Collection. All cell lines were cultured in RPMI-1640 medium (Sigma-Aldrich; Merck KGaA), supplemented with $10 \%$ fetal bovine serum and incubated in an atmosphere with $5 \% \mathrm{CO}_{2}$ at $37^{\circ} \mathrm{C}(13)$.

Human samples were resected from 114 patients with BC who had undergone surgery at Nagoya University Hospital between March 2002 and May 2007. The selected patients were those whose surveillance data for more than five years after surgery were available. All patients were females, and the median age was 53 years (range, 32-78 years). Primary BC and non-cancerous specimens and clinical data were collected from these patients. Clinical specimens were resected to $\sim 1.5 \mathrm{~mm}$ in diameter and frozen immediately at $-80^{\circ} \mathrm{C}$. Non-cancerous specimens were resected $>3 \mathrm{~cm}$ away from the edge of the tumor (12). The resected BC specimens were diagnosed histologically as $\mathrm{BC}$ and classified using the Union for International Cancer Control (UICC) staging system for BC (8th edition) (14). Adjuvant medication therapy was determined by physician discretion considering each patient's general condition, pathological features, and subtype $(12,13)$.

The present study complied with the Declaration of Helsinki and was approved by the Nagoya University Hospital Institutional Review Board (approval number: 2019-0028). Participants provided written informed consent for the use of their clinical samples and data.

Reverse transcription-quantitative polymerase chain reaction (RT-qPCR). MZB1, DNA damage inducible transcript 3 (DDIT3), DERL3, and XBP1 mRNA expression levels were evaluated using RT-qPCR. RNA was extracted from cell lines $\left(8.0 \times 10^{6}\right.$ cells per cell line) and from 114 patient $\mathrm{BC}$ and non-cancerous specimens using the RNeasy Mini kit (Qiagen $\mathrm{GmbH})$. cDNA was synthesized as previously described $(12,13,15)$. GAPDH mRNA levels were evaluated for normalizing $M Z B 1, D D I T 3, D E R L 3$, and XBP1 mRNA expression levels. The primers specific for each gene were as follows: $M Z B 1$ : Forward, 5'-CTCACAGGCCCAGGACTT AG-3' and reverse, 5'-TGTGGCTGACACCTTCTCTG-3', which generated a 219-bp product; DDIT3: Forward, 5'-AGC GACAGAGCCAAAATCAG-3' and reverse, 5'-TGCTTT CAGGTGTGGTGATG-3', which generated a 88-bp product; DERL3: Forward, 5'-CTCACTTTCCAGGCACCGT-3' and reverse, 5'-TAGTAGATATGGCCCACCGC-3', which generated a 110-bp product (12); XBPl: Forward, 5'-CAGACTACG TGCGCCTCTGC-3' and reverse, 5'-CTTCTGGGTAGA CCTCTGGG-3', which generated a 208-bp product (12); and GAPDH: Forward, 5'-GAAGGTGAAGGTCGGAGTC-3' and reverse, 5'-GAAGATGGTGATGGGATTTC-3', which generated a 226-bp product (3). SYBR Green PCR core reagent kit (Thermo Fisher Scientific, Inc.) was used for RT-qPCR with these cycling conditions: One cycle at $95^{\circ} \mathrm{C}$ for $10 \mathrm{~min}$, followed by 40 cycles at $95^{\circ} \mathrm{C}$ for $5 \mathrm{sec}$ and $60^{\circ} \mathrm{C}$ for $60 \mathrm{sec}$, using an ABI StepOnePlus real-time PCR System (Thermo Fisher Scientific, Inc.). The $2^{-\Delta \Delta C t}$ method was used for PCR quantification (16). All samples were assayed in triplicate. The mRNA expression levels of $M Z B 1, D D I T 3, D E R L 3$, and $X B P 1$ in each sample were obtained from the value divided by the $G A P D H$ value for normalization $(12,13,15)$.

Immunohistochemistry. Formalin-fixed, paraffin-embedded sections (4- $\mu \mathrm{m}$ thick) were constructed from blocks of resected specimens from $114 \mathrm{BC}$ patients. The resected specimens were fixed with $10 \%$ formalin for $48 \mathrm{~h}$. The slides were heated for 2 min for antigen retrieval with $1 \mathrm{mM}$ EDTA buffer. The blocking procedure was not conducted. The MZB1 rabbit polyclonal antibody (cat. no. 11454-1-AP; ProteinTech, Inc.), which was diluted at 1:100, was used for immunohistochemistry, and sections were incubated for $1 \mathrm{~h}$ at room temperature (3). Then, SignalStain Boost IHC Detection reagent (cat. no. 8114; Cell Signaling Technology, Inc.) was used for the secondary antibody, and sections were incubated for $30 \mathrm{~min}$ at room temperature. The entire cancerous area of each section was observed using an upright light microscope (Olympus Corporation; $\mathrm{x} 100$ and $\mathrm{x} 400$ magnification). The staining intensity of the cytoplasm in cancer cells was evaluated and the intensity was divided into three groups: 'Negative', 'weak', and 'strong'. Subsequently, 'weak' and 'strong' were combined and defined as 'positive'.

Statistical analysis. Differences in the levels of MZB1 mRNA between two groups were evaluated using a Mann-Whitney test. Correlations between MZB1, DDIT3, DERL3, and $X B P 1$ mRNA levels were analyzed using Spearman's rank correlation test. The associations between mRNA or protein expression levels of MZB1 and patient clinicopathological factors were analyzed using the $\chi^{2}$ test. The Kaplan-Meier method was utilized for evaluating disease-free survival (DFS) and overall survival (OS) rates, and the survival curves were compared using the log-rank test. For multivariate regression analysis, the Cox proportional hazards model was utilized to identify prognostic factors. Other than MZB1 positivity, the variables were those considered to affect breast cancer prognosis, including age, tumor size, lymph node metastasis, and biological statuses. Next, variables for which $\mathrm{P}<0.05$ were entered into the final model. JMP 12 (SAS Institute, Inc.) was 
employed for the statistical analysis, and $\mathrm{P}<0.05$ was considered to indicate a statistically significant difference.

\section{Results}

MZB1 mRNA expression levels in BC cell lines. MZB1 mRNA expression in $13 \mathrm{BC}$ cell lines and two non-cancerous cell lines from the mammary gland were evaluated (Fig. 1). The estrogen receptor (ER), progesterone receptor $(\mathrm{PgR})$, and HER2 statuses of the cell lines have been evaluated in previous studies $(17,18)$. MZBI mRNA was detectable in four ER-positive BC cell lines, but not in the other nine BC and both non-cancerous cell lines. When $M Z B 1$ mRNA expression levels were compared between ER-positive and ER-negative BC cell lines, MZB1 mRNA expression levels in ER-positive cell lines were significantly higher than those in ER-negative $\mathrm{BC}$ cell lines $(\mathrm{P}=0.009)$.

Patient characteristics. The UICC stage distribution of 114 patients was as follows: stage 0 , six patients; stage I, 29 patients; stage II, 56 patients; and stage III, 23 patients. T stage was distributed as follows: Tis (ductal carcinoma in situ), six patients; T1, 43 patients; T2, 54 patients; T3, six patients; and T4, five patients. Half of the patients had lymph node metastasis. The median follow-up duration was 123 months (range, 8-191 months) or until death. ER, PgR, and HER2 statuses, determined from immunohistochemistry tests in primary tumors, were as follows: ER-positive, $n=86$; ER-negative, $n=28$; PgR-positive, $n=76$; PgR-negative, $n=38$; HER2-positive, $n=25$; HER2-negative, $n=80$ (data missing for nine patients); triple-negative, $n=12$; and non-triple-negative, $\mathrm{n}=101$ (data missing for one patient). Patients whose tumor expressed at least one of ER, PgR, or HER2 were defined as 'non-triple-negative'. As eight patients out of nine whose HER2 statuses were unknown showed ER-positivity, they were categorized as non-triple-negative.

Association between MZB1 mRNA expression levels and patient clinicopathological factors. MZBI is expressed, not only in BC cells, but also in the cellular components of non-cancerous specimens (e.g. mammary cells and lymphocytes). To evaluate $M Z B 1 \mathrm{mRNA}$ expression levels in clinical $\mathrm{BC}$ samples, the ' $M Z B 1 \mathrm{C} / \mathrm{N}$ ratio', a ratio of $M Z B 1 \mathrm{mRNA}$ expression levels between $\mathrm{BC}$ and adjacent non-cancerous specimens, was adopted aiming to reduce the effects of $M Z B I$ expression on non-cancerous tissues. There were no significant differences between Tis/T1 $(n=49)$ and T2/T3/T4 patients $(\mathrm{n}=65 ; \mathrm{P}=0.134)$. However, in patients with lymph node metastasis ( $\mathrm{n}=57$ ), the $M Z B 1 \mathrm{C} / \mathrm{N}$ ratio tended to be higher than in lymph node-negative patients ( $\mathrm{n}=57 ; \mathrm{P}=0.064)$, and stage III patients $(\mathrm{n}=23)$ had a significantly higher $M Z B 1 \mathrm{C} / \mathrm{N}$ ratio compared with stage 0/I/II patients $(\mathrm{n}=91 ; \mathrm{P}=0.009$; Fig. $2 \mathrm{~A})$. Patients whose $M Z B 1 \mathrm{C} / \mathrm{N}$ ratios were higher than three were placed into a 'high $M Z B 1$ group' $(\mathrm{n}=33)$, and the remaining patients were designated as 'others' $(\mathrm{n}=81)$. The high $M Z B 1$ group was associated with lymph node metastasis $(\mathrm{P}=0.007)$ and a more advanced UICC pathological stage $(\mathrm{P}=0.006$; Table I). As $M Z B 1$ mRNA expression levels were detected in only ER-positive cells among BC cell lines, $M Z B 1$ mRNA expression levels were evaluated in ER-positive patients

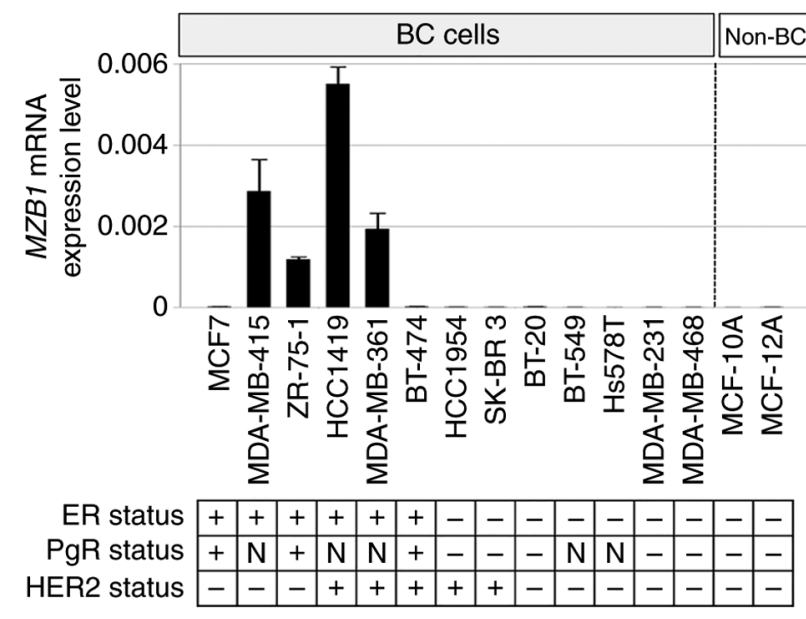

Figure 1. Assessment of $M Z B 1$ mRNA expression levels in cell lines. Bar graphs show $M Z B 1$ mRNA levels in 13 BC cell lines and two non-cancerous breast cell lines. $M Z B 1$ expression was detected in four estrogen receptor-positive $\mathrm{BC}$ cell lines, but it was not detected in the other nine $\mathrm{BC}$ and non-cancerous mammary cell lines. The ER, PgR, and HER2 statuses of the cell lines were referred from the previous studies $(17,18)$. BC, breast cancer cell lines; non-BC, non-cancerous breast cell lines; ER, estrogen receptor; HER2, human epidermal growth factor 2; PgR, progesterone receptor; N, no previous data available; MZB1, marginal zone B and B1 cell-specific protein.

$(\mathrm{n}=86)$. Stage III patients $(\mathrm{n}=13)$ had a significantly higher $M Z B 1 \mathrm{C} / \mathrm{N}$ ratio than stage $0 / \mathrm{I} / \mathrm{II}$ patients $(\mathrm{n}=73 ; \mathrm{P}=0.003)$. Furthermore, the high $M Z B 1$ group $(\mathrm{n}=28)$ was associated with lymph node metastasis $(\mathrm{P}=0.004)$ and a more advanced UICC pathological stage $(\mathrm{P}=0.002)$, compared with others $(\mathrm{n}=58)$. In summary, $M Z B 1$ mRNA expression was associated with lymph node metastasis and a more advanced stage in patients with ER-positive BC.

As MZB1 has been reported to exist in the endoplasmic reticulum of cancer cells (5), the correlations between mRNA expression levels of $M Z B 1, X B P 1$, and DDIT3, UPR-related molecules $(11,19)$, were evaluated. Although there was no significant correlation between mRNA expression levels of $M Z B 1$ and $X B P 1$ (correlation coefficient, 0.052; $\mathrm{P}=0.584$; Fig. 2B), $M Z B 1$ mRNA expression was significantly correlated with that of DDIT3 (correlation coefficient, 0.421; $\mathrm{P}<0.0001$; Fig. 2B). Furthermore, when $M Z B 1$ and DERL3 mRNA levels were evaluated, there was a significant correlation (correlation coefficient, $0.669 ; \mathrm{P}<0.0001 ;$ Fig. 2B). These results suggested that MZB1 serves some role associated with UPR pathways.

Assessment of MZB1 protein expression status using immunohistochemistry. As mRNA extracted from cancer specimens may contain mRNA derived from stromal cells, immunohistochemistry of MZB1 was conducted to assess the significance of its expression in BC cells. Among 114 patients with breast cancer, $\mathrm{BC}$ specimens from patients did not express MZB1 (determined as negative), and those from 35 and 29 patients expressed MZB1 weakly and strongly, respectively (determined as positive, Fig. 3A). There was no significant association between MZB1 positivity and T status $(\mathrm{P}=0.181)$, node status $(\mathrm{P}=0.706)$, or pathological stage $(\mathrm{P}=0.326)$. However, patients' age $(\leq 60$-year-old; $\mathrm{P}=0.009)$, ER-positivity $(\mathrm{P}=0.003), \mathrm{PgR}$-positivity $(\mathrm{P}=0.003)$, and 

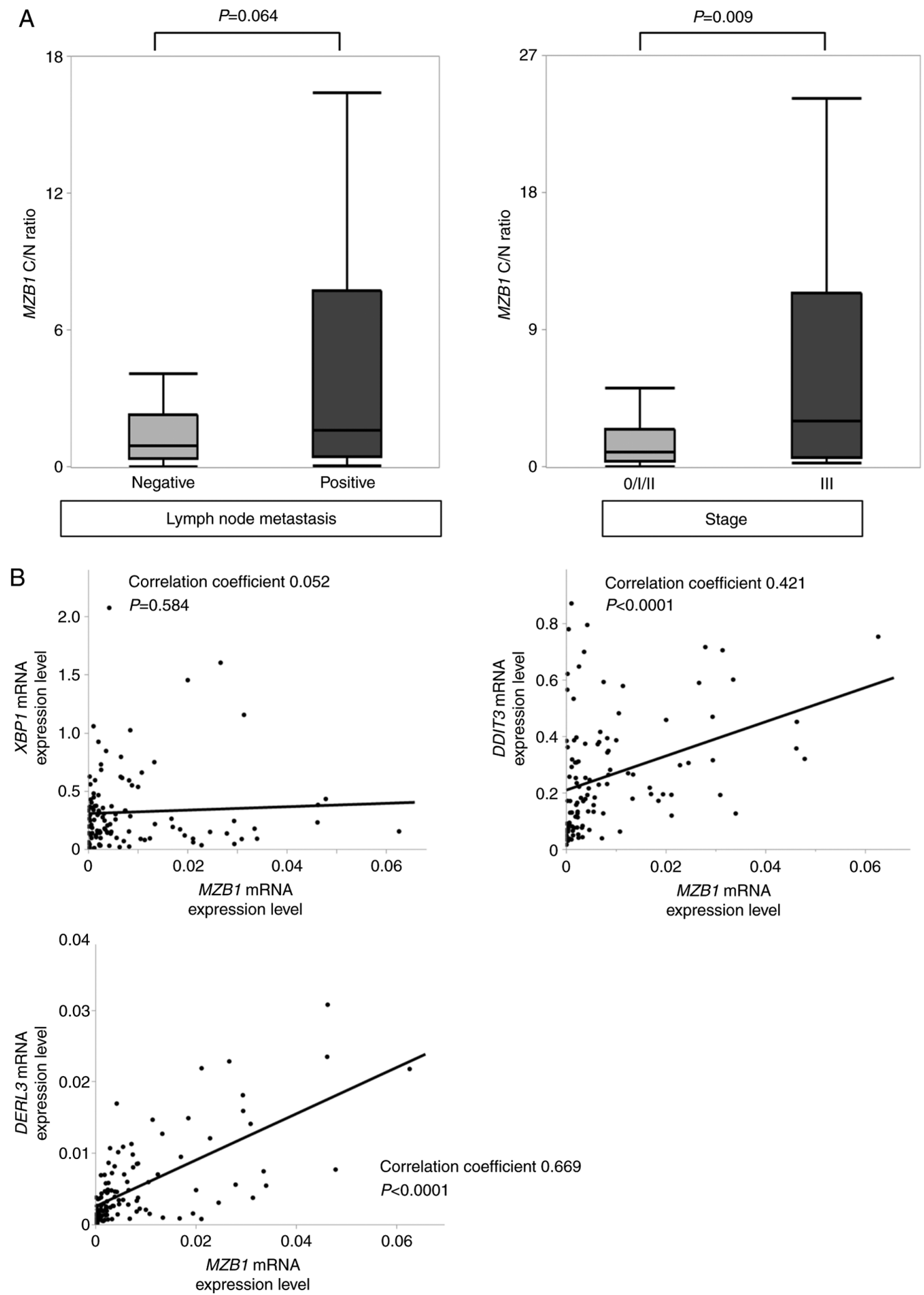

Figure 2. Assessment of $M Z B 1$ mRNA expression levels in breast cancer specimens. (A) $M Z B 1 \mathrm{C} / \mathrm{N}$ ratios in patients with lymph node metastasis tended to be higher compared with those in lymph node-negative patients. Stage III patients had significantly higher $M Z B I \mathrm{C} / \mathrm{N}$ ratios compared with stage $0 / \mathrm{I} / \mathrm{II}$ patients. (B) Although there was no correlation between $M Z B 1$ and $X B P 1$ mRNA expression levels, $M Z B 1 \mathrm{mRNA}$ expression level was significantly correlated with those of DDIT3 and DERL3 in 114 patients with breast cancer. MZB1, marginal zone B and B1 cell-specific protein.

non-triple-negativity $(\mathrm{P}=0.023)$ were significantly associated with MZB1 positivity (Table II). There were no differences between MZB1 positive and negative groups regarding DFS $(\mathrm{P}=0.478)$ or $\mathrm{OS}(\mathrm{P}=0.996)$.
$M Z B 1$ mRNA expression levels were detected in ER-positive BC cell lines, and high $M Z B 1 \mathrm{C} / \mathrm{N}$ levels were associated with a more advanced pathological stage in specimens from patients with BC. Furthermore, MZB1 exhibited 
Table I. Association between MZB1 mRNA expression and clinicopathological characteristics in 114 patients with breast cancer.

\begin{tabular}{|c|c|c|c|}
\hline Clinicopathological parameter & High $M Z B 1$ group $(\mathrm{n}=33)$ & Other $(\mathrm{n}=81)$ & P-value \\
\hline Age & & & 0.246 \\
\hline$\leq 60$ years & 23 & 47 & \\
\hline$>60$ years & 10 & 34 & \\
\hline Histology & & & 0.401 \\
\hline Ductal carcinoma in situ & 0 & 6 & \\
\hline Invasive ductal carcinoma & 31 & 68 & \\
\hline Invasive lobular carcinoma & 1 & 3 & \\
\hline Other & 1 & 4 & \\
\hline UICC $\mathrm{T}$ factor & & & 0.081 \\
\hline Tis/T1 & 10 & 39 & \\
\hline $\mathrm{T} 2 / \mathrm{T} 3 / \mathrm{T} 4$ & 23 & 42 & \\
\hline Node status & & & $0.007^{\mathrm{a}}$ \\
\hline Negative & 10 & 47 & \\
\hline Positive & 23 & 34 & \\
\hline UICC pathological stage & & & $0.006^{\mathrm{a}}$ \\
\hline $0 / \mathrm{I} / \mathrm{II}$ & 21 & 70 & \\
\hline III & 12 & 11 & \\
\hline ER status & & & 0.136 \\
\hline Positive & 28 & 58 & \\
\hline Negative & 5 & 23 & \\
\hline PgR status & & & 0.381 \\
\hline Positive & 20 & 56 & \\
\hline Negative & 13 & 25 & \\
\hline HER2 status & & & 0.944 \\
\hline Positive & 8 & 17 & \\
\hline Negative & 25 & 55 & \\
\hline Unknown & 0 & 9 & \\
\hline Triple-negative & & & 0.312 \\
\hline Yes & 2 & 10 & \\
\hline No & 31 & 70 & \\
\hline Unknown & 0 & 1 & \\
\hline Adjuvant therapy & & & $0.032^{\mathrm{a}}$ \\
\hline Endocrine therapy alone & 12 & 33 & \\
\hline Chemotherapy alone & 5 & 15 & \\
\hline Endocrine and chemotherapy & 16 & 21 & \\
\hline None & 0 & 12 & \\
\hline
\end{tabular}

P-values were determined using a $\chi^{2}$ test. ${ }^{\mathrm{a}} \mathrm{P}<0.05$. ER, estrogen receptor; HER2, human epidermal growth factor 2; MZB1, marginal zone B and B1 cell-specific protein; PgR, progesterone receptor; UICC, Union for International Cancer Control.

increased expression in ER-positive patients (Table II). These results implied that there is an association between MZB1 and ER-positive BC. In ER-positive patients $(n=86)$, DFS rates was significantly poorer in MZB1-positive patients $(n=55)$ compared with MZB1-negative patients $(n=31 ; 5$-year DFS rates: MZB1-positive group, $80.0 \%$; negative group, $93.4 \%$; $\mathrm{P}=0.026$; Fig. 3B). By contrast, OS in MZB1-positive patients did not differ from that in MZB1-negative patients (5-year OS rates: MZB1-positive group, 94.5\%; negative group, $96.8 \%$; $\mathrm{P}=0.260$; Fig. 3C). Multivariate analysis of DFS identified 'lymph node metastasis' (HR, 7.81; 95\% CI, 2.10-50.9; $\mathrm{P}=0.001)$ and 'MZB1 positivity' (HR, 4.30; 95\% CI, 1.21-27.4; $\mathrm{P}=0.022$ ) as independent prognostic factors (Table III).

\section{Discussion}

The present study has demonstrated the significance of MZB1 expression, particularly in ER-positive BC. In cell lines, $M Z B 1$ expression was only detectable in ER-positive $\mathrm{BC}$ cells, but not in ER-negative or non-cancerous cells. In 
A

MZB1 immunohistochemical staining
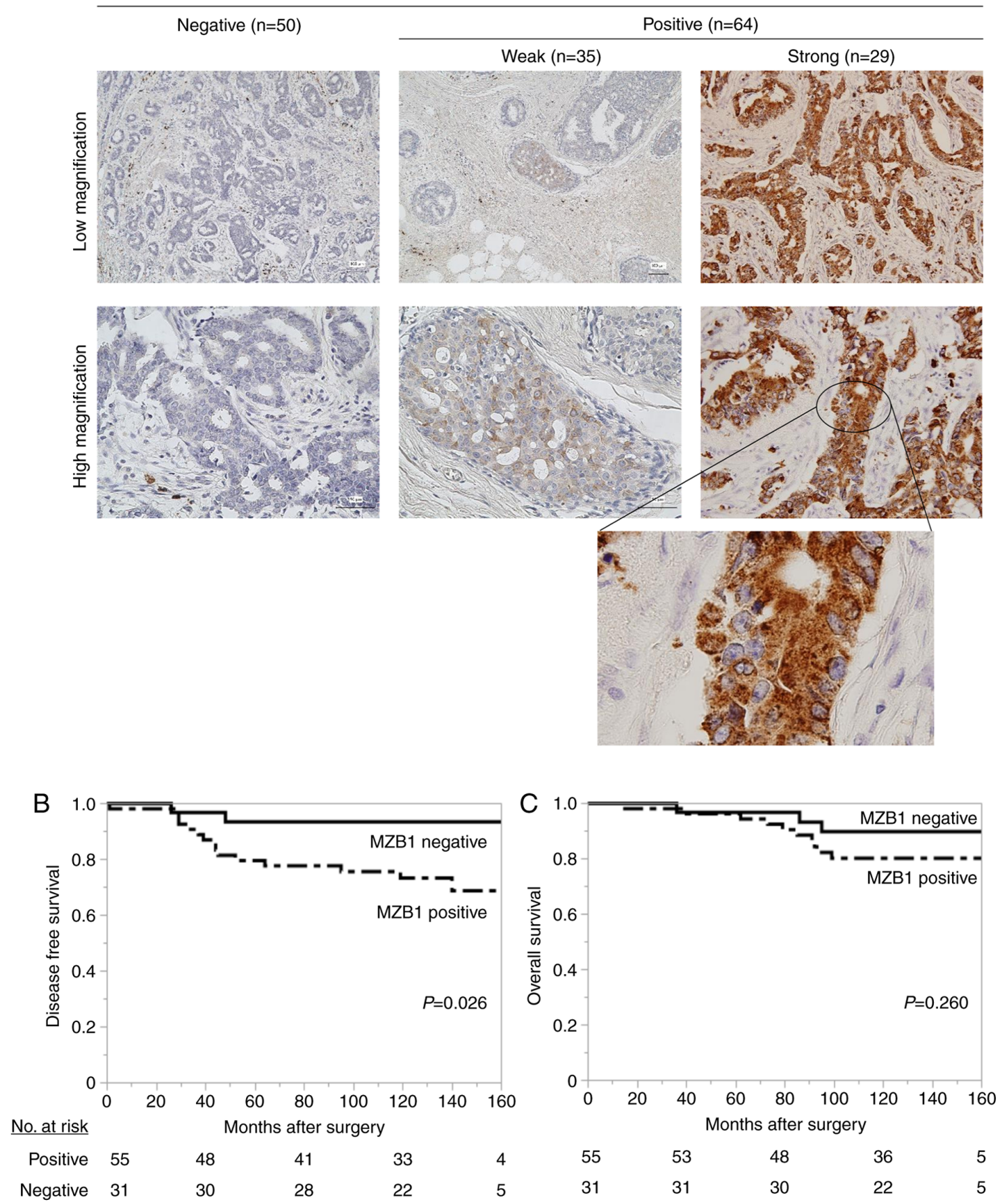

Figure 3. Evaluation of MZB1 protein expression using immunohistochemistry. (A) Among 114 patients with breast cancer, MZB1 expression was observed in 64 cases, including 35 strongly and 29 weakly stained cases (determined as positive), whereas 50 cases did not express MZB1 (determined as negative). The enlarged picture shows that MZB1 staining was observed in the cytoplasm of cancer cells. (B) In estrogen receptor-positive patients, MZB1-positive patients had poorer disease-free survival rates than MZB1-negative patients. (C) Overall survival rates did not differ between MZB1-positive and negative patients. MZB1, marginal zone B and B1 cell-specific protein.

clinical samples, a higher $M Z B 1 \mathrm{C} / \mathrm{N}$ ratio was associated with lymph node metastasis and a more advanced UICC stage in patients with ER-positive BC. Notably, MZB1-positive expression, performed using immunohistochemistry, indicated a poor prognosis, and was an independent prognostic factor in patients with ER-positive BC.

In recent years, attention has been focused on the endoplasmic reticulum stress response, including UPR in cancer cells (19). UPR is involved in protein-folding homeostasis against various stresses and is enhanced in cancer cells, resulting in cancer progression (19). As UPR activates endoplasmic reticulum chaperones that stabilize protein-folding to promote cancer cell survival, proliferation, angiogenesis, metastasis, and therapy resistance (20), UPR-related pathways or molecules have been considered attractive candidates for novel biomarkers or therapeutic targets.

MZB1 was originally identified as a molecule that regulates the correct surface presentation and secretion of $\operatorname{IgM}$, 
Table II. Association between immunohistochemical MZB1 expression and clinicopathological characteristics in 114 patients with breast cancer.

\begin{tabular}{|c|c|c|c|}
\hline Clinicopathological parameter & MZB1-positive group $(n=64)$ & MZB1-negative group $(n=50)$ & P-value \\
\hline Age & & & $0.009^{\mathrm{a}}$ \\
\hline$\leq 60$ years & 46 & 24 & \\
\hline$>60$ years & 18 & 26 & \\
\hline Histology & & & 0.477 \\
\hline Ductal carcinoma in situ & 2 & 4 & \\
\hline Invasive ductal carcinoma & 56 & 43 & \\
\hline Invasive lobular carcinoma & 2 & 2 & \\
\hline Other & 4 & 1 & \\
\hline UICC $\mathrm{T}$ factor & & & 0.181 \\
\hline Tis/T1 & 24 & 25 & \\
\hline $\mathrm{T} 2 / \mathrm{T} 3 / \mathrm{T} 4$ & 40 & 25 & \\
\hline Node status & & & 0.706 \\
\hline Negative & 31 & 26 & \\
\hline Positive & 33 & 24 & \\
\hline UICC pathological stage & & & 0.326 \\
\hline $0 / \mathrm{I} / \mathrm{II}$ & 49 & 42 & \\
\hline III & 15 & 8 & \\
\hline ER status & & & $0.003^{\mathrm{a}}$ \\
\hline Positive & 55 & 31 & \\
\hline Negative & 9 & 19 & \\
\hline PgR status & & & $0.003^{\mathrm{a}}$ \\
\hline Positive & 50 & 26 & \\
\hline Negative & 14 & 24 & \\
\hline HER2 status & & & 0.878 \\
\hline Positive & 13 & 12 & \\
\hline Negative & 43 & 37 & \\
\hline Unknown & 8 & 1 & \\
\hline Triple-negative & & & $0.023^{\mathrm{a}}$ \\
\hline Yes & 3 & 9 & \\
\hline No & 60 & 41 & \\
\hline Unknown & 1 & 0 & \\
\hline Adjuvant therapy & & & 0.175 \\
\hline Endocrine therapy alone & 27 & 18 & \\
\hline Chemotherapy alone & 9 & 11 & \\
\hline Endocrine and chemotherapy & 24 & 13 & \\
\hline None & 4 & 8 & \\
\hline
\end{tabular}

P-values were determined using a $\chi^{2}$ test. ${ }^{\mathrm{a}} \mathrm{P}<0.05$. ER, estrogen receptor; HER2, human epidermal growth factor 2; MZB1, marginal zone B and B1 cell-specific protein; PgR, progesterone receptor; UICC, Union for International Cancer Control.

which is located in the endoplasmic reticulum in B lymphocytes $(21,22)$. It has been reported that MZB1 is involved in the stabilization and secretion of $\operatorname{Ig} \mathrm{A}$ and $\operatorname{IgM}$ as a molecular chaperone in cooperation with other chaperones, including GRP78 and GRP94 (6). Conversely, in malignant tumor cells, the role of MZB1 has not been fully clarified. Our previous study reported that DERL3, which is located in the endoplasmic reticulum and is activated in the UPR pathway, promotes $\mathrm{BC}$ progression, and that DERL3 expression was associated with more aggressive clinical features in BC (12). Notably, $M Z B 1$ expression was positively correlated with not only DDIT3 expression but also DERL3 expression in the clinical BC specimens, suggesting the possibility that MZB1 is somewhat associated with UPR pathways in BC cells.

Several studies have reported inconsistent roles for MZB1 in various malignancies. Our group previously demonstrated the tumor-suppressive roles of MZB1 and showed that low $M Z B 1$ expression was an independent poor prognostic factor 
Table III. Prognostic factors for disease-free survival in 86 patients with estrogen receptor-positive breast cancer.

\begin{tabular}{|c|c|c|c|c|c|c|c|}
\hline \multirow[b]{2}{*}{ Variable } & \multirow[b]{2}{*}{$\mathrm{n}$} & \multicolumn{3}{|c|}{ Univariate } & \multicolumn{3}{|c|}{ Multivariate } \\
\hline & & Hazard ratio & $95 \% \mathrm{CI}$ & P-value & Hazard ratio & $95 \% \mathrm{CI}$ & P-value \\
\hline Age, $>60$ years & 31 & 0.89 & $0.28-2.39$ & 0.820 & & & \\
\hline Tumor size, $>2 \mathrm{~cm}$ & 46 & 4.48 & $1.46-19.4$ & $0.007^{\mathrm{a}}$ & 2.19 & $0.69-9.79$ & 0.197 \\
\hline Node status positive & 42 & 9.88 & $2.78-62.7$ & $0.001^{\mathrm{a}}$ & 7.81 & $2.10-50.9$ & $0.001^{\mathrm{a}}$ \\
\hline HER2-positive & 9 & 2.95 & $0.82-8.49$ & 0.091 & & & \\
\hline MZB1-positive & 55 & 4.58 & $1.29-29.1$ & $0.016^{\mathrm{a}}$ & 4.30 & $1.21-27.4$ & $0.022^{\mathrm{a}}$ \\
\hline
\end{tabular}

${ }^{a} \mathrm{P}<0.05$. CI, confidence interval; HER2, human epidermal growth factor 2; MZB1, marginal zone B and B1 cell-specific protein.

in gastric cancer (3). In hepatocellular carcinoma, patients with positive MZB1 expression using immunohistochemistry experienced a better prognosis (5). Conversely, in chronic lymphocytic leukemia, high $M Z B 1$ expression was associated with poorer survival (4). In the present study, MZB1 was considered to be associated with tumor-progression in $\mathrm{BC}$, because its $\mathrm{C} / \mathrm{N}$ ratio was higher in patients with more advanced disease. Furthermore, in ER-positive patients, MZB1 expression was an independent prognostic factor that was indicative of poor DFS rates. Although MZB1-positive patients tended to show poorer OS rates, there was no significant difference. This may be because metastatic BC patients, particularly those with ER positivity, have various treatment options, which leads to long survival times following recurrence. Notably, $M Z B 1$ expression was detectable in only four ER-positive cell lines among thirteen BC cell lines, and MZB1 was more likely to be expressed in ER-positive clinical specimens, suggesting that MZB1 expression may be more activated in the ER-positive BC subtype. However, it should be noted that not all ER-positive BC cell lines and clinical specimens expressed MZB1. In ER-positive BC, estrogen acting via estrogen receptor $\alpha(E R \alpha)$ induces activation of UPR components, including inositol requiring enzyme 1 (IRE1) and GRP78, which confer estrogen-ER $\alpha$-induced cell proliferation and resistance to endocrine therapy and chemotherapy $(23,24)$. The results of the present study suggested that MZB1 expression reflects the activation of the UPR pathway in BC cells, leading to a poor prognosis. However, the present study is not capable of determining whether MZB1 serves any oncogenic role due to the lack of mechanistic experiments.

Recently, although chemotherapy, endocrine therapy, anti-HER2 drugs, molecular-targeting drugs, and immunotherapy have been used in the treatment of patients with metastatic BC, no drugs that target pathways related to the endoplasmic reticulum stress response are available. However, in preclinical research, the UPR pathway and molecular chaperones are receiving attention as potential novel therapeutic targets. For example, ganetespib, which inhibits heat shock protein 90 (HSP90), also known as GRP94, was shown to suppress MAPK, AKT, and mTOR pathways in BC (25), and it has been clinically tested (26). In addition, other studies have shown the synergistic effects of combining conventional chemotherapy with UPR inhibitors $(19,26)$. 'Targeting UPR' has been recognized as one of the novel therapeutic strategies (19), and the present study may aid in understanding the UPR pathways in BC.

There are certain limitations to the present study. As mentioned earlier, as this study did not evaluate the function of MZB1, it remains uncertain how MZB1 works in $\mathrm{BC}$ cells. Additionally, MZB1 is expressed not only in $\mathrm{BC}$ cells but also in normal mammary and stromal cells (e.g. lymphocytes), which may cause discrepancies depending on the analytic methods. Although RT-qPCR in BC cell lines and immunohistochemistry in clinical samples evaluated the status of MZB1 expression in BC cells, MZB1 mRNA expression levels in clinical samples did not exclude those derived from stromal cells. For example, in the present study, $M Z B 1$ mRNA expression levels in ER-positive patients were not higher than those in ER-negative patients, unlike the results of BC cell lines and immunohistochemistry. Finally, although the present study showed that MZB1 positivity was a poor prognostic marker in our cohort, it should be validated in different cohorts to determine the utility of MZB1 as a novel biomarker.

In conclusion, the present study has raised the possibility of MZB1 acting as a prognostic marker in patients with ER-positive BC. Pathways related to the endoplasmic reticulum stress response are considered attractive targets to develop novel biomarkers and therapeutic strategies.

\section{Acknowledgements}

The authors would like to thank Professor David Sidransky, Director of the Otolaryngology Department of Johns Hopkins University School of Medicine (Baltimore, MD, USA) for providing the BT-474, MCF-7, and MCF-12A cell lines.

\section{Funding}

The present study was supported by JSPS KAKENHI of Japan (grant no. JP7119K16795) and Hibino Foundation of Japan (grant no. 2600006536).

\section{Availability of data and materials}

The data used and/or analyzed during the present study can be obtained from the corresponding author upon reasonable request. 


\section{Authors' contributions}

MS and MK conceived and designed the study. MW, MS, TIn, and TIc conducted the experiments. MW and MS analyzed the data and wrote the manuscript. MS, NM, YT, DT, NT, and TK contributed the acquisition and interpretation of patient data. TIn, TIc, IS, NM, YT, DT, NT, MK, TK, YK, and MN reviewed and revised the manuscript. The final manuscript was read and approved by all authors.

\section{Ethics approval and consent to participate}

The present study was approved by the Institutional Review Board of Nagoya University Graduate School of Medicine (reference number: 2019-0028). Written informed consent was obtained from participants for the use of samples and data.

\section{Patient consent for publication}

Participants in this study granted written informed consent for publication.

\section{Competing interests}

The authors declare that they have no competing interests.

\section{References}

1. Global Burden of Disease Cancer Collaboration; Fitzmaurice C, Allen C, Barber RM, Barregard L, Bhutta ZA, Brenner H, Dicker DJ, Chimed-Orchir O, Dandona R, et al: Global, regional, and national cancer incidence, mortality, years of life lost, years lived with disability, and Disability-adjusted life-years for 32 cancer groups, 1990 to 2015 a systematic analysis for the global burden of disease study. JAMA Oncol 3: 524-548, 2017.

2. Iwata $\mathrm{H}$ : Future treatment strategies for metastatic breast cancer: Curable or incurable? Breast Cancer 19: 200-205, 2012.

3. Kanda M, Tanaka C, Kobayashi D, Tanaka H, Shimizu D, Shibata M, Takami H, Hayashi M, Iwata N, Niwa Y, et al: Epigenetic suppression of the immunoregulator MZB1 is associated with the malignant phenotype of gastric cancer. Int J Cancer 139: 2290-2298, 2016

4. Herold T, Mulaw MA, Jurinovic V, Seiler T, Metzeler KH, Dufour A, Schneider S, Kakadia PM, Spiekermann K, Mansmann U, et al: High expression of MZB1 predicts adverse prognosis in chronic lymphocytic leukemia, follicular lymphoma and diffuse large B-cell lymphoma and is associated with a unique gene expression signature. Leuk Lymphoma 54: 1652-1657, 2013.

5. Matsumura S, Imoto I, Kozaki K, Matsui T, Muramatsu T, Furuta M, Tanaka S, Sakamoto M, Arii S and Inazawa J: Integrative array-based approach identifies MZB1 as a frequently methylated putative tumor suppressor in hepatocellular carcinoma. Clin Cancer Res 18: 3541-3551, 2012.

6. Rosenbaum M, Andreani V, Kapoor T, Herp S, Flach H, Duchniewicz $M$ and Grosschedl R: MZB1 is a GRP94 cochaperone that enables proper immunoglobulin heavy chain biosynthesis upon ER stress. Genes Dev 28: 1165-1178, 2014

7. Cox JS, Shamu CE and Walter P: Transcriptional induction of genes encoding endoplasmic reticulum resident proteins requires a transmembrane protein kinase. Cell 73: 1197-1206, 1993.

8. Hochachka PW, Buck LT, Doll CJ and Land SC: Unifying theory of hypoxia tolerance: Molecular/metabolic defense and rescue mechanisms for surviving oxygen lack. Proc Natl Acad Sci USA 93: 9493-9498, 1996.

9. Koumenis C: ER stress, hypoxia tolerance and tumor progression. Curr Mol Med 6: 55-69, 2006.
10. Fernandez PM, Tabbara SO, Jacobs LK, Manning FC, Tsangaris TN, Schwartz AM, Kennedy KA and Patierno SR: Overexpression of the glucose-regulated stress gene GRP78 in malignant but not benign human breast lesions. Breast Cancer Res Treat 59: 15-26, 2000.

11. Fujimoto T, Onda M, Nagai H, Nagahata T, Ogawa K and Emi M: Upregulation and overexpression of human X-box binding protein 1 (hXBP-1) gene in primary breast cancers. Breast Cancer 10: 301-306, 2003.

12. Shibata M, Kanda M, Tanaka H, Umeda S, Miwa T, Shimizu D, Hayashi M,Inaishi T, Miyajima N, Adachi Y, et al: Overexpression of Derlin 3 is associated with malignant phenotype of breast cancer cells. Oncol Rep 38: 1760-1766, 2017.

13. Shibata M, Kanda M, Shimizu D, Tanaka H, Umeda S, Hayashi M, Inaishi T, Miyajima N, Adachi Y, Takano Y, et al: Expression of regulatory factor $\mathrm{X} 1$ can predict the prognosis of breast cancer. Oncol Lett 13: 4334-4340, 2017.

14. Cserni G, Chmielik E, Cserni B and Tot T: The new TNM-based staging of breast cancer. Virchows Archi 472: 697-703, 2018.

15. Shibata M, Kanda M, Shimizu D, Tanaka H, Umeda S, Miwa T, Hayashi M, Inaishi T, Miyajima N, Adachi Y, et al: RASEF expression correlates with hormone receptor status in breast cancer. Oncol Lett 16: 7223-7230, 2018.

16. Livak KJ and Schmittgen TD: Analysis of relative gene expression data using real-time quantitative PCR and the 2(-Delta Delta $\mathrm{C}(\mathrm{T})$ ) method. Methods 25: 402-408, 2001.

17. Finn RS, Dering J, Conklin D, Kalous O, Cohen DJ, Desai AJ, Ginther C, Atefi M, Chen I, Fowst C, et al: PD 0332991, a selective cyclin D kinase 4/6 inhibitor, preferentially inhibits proliferation of luminal estrogen receptor-positive human breast cancer cell lines in vitro. Breast Cancer Res 11: R77, 2009.

18. Subik K, Lee JF, Baxter L, Strzepek T, Costello D, Crowley P, Xing L, Hung MC, Bonfiglio T, Hicks DG and Tang P: The expression patterns of ER, PR, HER2, CK5/6, EGFR, Ki-67 and AR by immunohistochemical analysis in breast cancer cell lines. Breast Cancer (Auckl) 4: 35-41, 2010.

19. McGrath EP, Logue SE, Mnich K, Deegan S, Jäger R, Gorman AM and Samali A: The unfolded protein response in breast cancer. Cancers (Basel) 10: 344, 2018.

20. Ansa-Addo EA, Thaxton J, Hong F, Wu BX, Zhang Y, Fugle CW, Metelli A, Riesenberg B, Williams K, Gewirth DT, et al: Clients and oncogenic roles of molecular chaperone gp96/grp94. Curr Top Med Chem 16: 2765-2778, 2016.

21. Belkaya S, Murray SE, Eitson JL, de la Morena MT, Forman JA and van Oers NS: Transgenic expression of microRNA-185 causes a developmental arrest of T cells by targeting multiple genes including Mzb1. J Biol Chem 288: 30752-30762, 2013.

22. Flach H, Rosenbaum M, Duchniewicz M, Kim S, Zhang SL, Cahalan MD, Mittler G and Grosschedl R: Mzb1 protein regulates calcium homeostasis, antibody secretion, and integrin activation in innate-like B cells. Immunity 33: 723-735, 2010.

23. Rajapaksa G, Thomas $\mathrm{C}$ and Gustafsson JÅ: Estrogen signaling and unfolded protein response in breast cancer. J Steroid Biochem Mol Biol 163: 45-50, 2016.

24. Andruska N, Zheng X, Yang X, Helferich WG and Shapiro DJ: Anticipatory estrogen activation of the unfolded protein response is linked to cell proliferation and poor survival in estrogen receptor $\alpha$-positive breast cancer. Oncogene 34: 3760-3769, 2015

25. Friedland JC, Smith DL, Sang J, Acquaviva J, He S, Zhang C and Proia DA: Targeted inhibition of Hsp90 by ganetespib is effective across a broad spectrum of breast cancer subtypes. Invest New Drugs 32: 14-24, 2014.

26. Jhaveri K, Wang R, Teplinsky E, Chandarlapaty S, Solit D, Cadoo K, Speyer J, D'Andrea G, Adams S, Patil S, et al: A phase I trial of ganetespib in combination with paclitaxel and trastuzumab in patients with human epidermal growth factor receptor-2 (HER2)-positive metastatic breast cancer. Breast Cancer Res 19: 89, 2017.

This work is licensed under a Creative Commons Attribution-NonCommercial-NoDerivatives 4.0 International (CC BY-NC-ND 4.0) License. 